\title{
THE IMPACT OF AWARENESS CAMPAIGN AND REHABILITATION ON THE ASSOCIATION BETWEEN QUALITY OF HEALTH, LOW- STIGMA, TRANSPORTATION, AND HEALTH- SEEKING BEHAVIOR AMONG OBSTETRIC FISTULA PATIENTS IN NIGERIA: A PROPOSED CONCEPTUAL MODEL
}

\author{
Muhammad Anka Nasiru \\ Department of Nursing Sciences, \\ Usmanu Danfodiyo University Sokoto, Nigeria
}

\author{
Abdurrahman Suleman Maru \\ Department of Nursing Sciences. \\ Usmanu Danfodiyo University Sokoto, Nigeria
}

\begin{abstract}
The objective of this study was to provide a graphic model that explains the constructs of the impact of the awareness campaign, rehabilitation, quality of health, low-stigma, transportation and health-seeking behavior among fistula patients in Nigeria. Explicitly, this study proposed a research model that as soon as validated; will be extended further to evaluate the hypothesized associations between the important variables of this study. To proffer answers to the research problem stated through this paper, the study will utilize mixed methods research design (pragmatic research orientation) in the subsequent research. This study consists of 6 main research constructs in the proposed conceptual model that when validated, they will be employed to assess the impact of the awareness campaign and rehabilitation programs, combined with quality of health, low-stigma, and transportation in strengthening the obstetric fistula women to seek for competent healthcare facilities in Nigeria.
\end{abstract}

Keywords - Awareness campaign, rehabilitation, quality of health, low-stigma, transportation, health-seeking behavior, obstetric fistula, conceptual model

\section{INTRODUCTION}

Obstetric fistula (OF) is a destructive wound suffered by women during delivery due to protracted labor (FMOH, 2012). OF is an opening between the vagina and urinary bladder or rectum (Wall, 2012). Globally, an estimate shows that out of the 140 million women of reproductive age that delivers babies annually, almost 25 million suffered from pregnancy-related complications following delivery (Siddle, Mwambingu, Malinga, \& Fiander 2013). Additionally, in Sub-
Saharan Africa and Asia alone, there are an estimated 1.5-2 million women of generative age who live with the burden of untreated cases of OF disease (FMOH, 2012). In Nigeria, it was estimated that around 1 million women suffer from OF with practically 20,000 new cases of the disease arising year after year (FMOH, 2012). Compounding the devastating injury is that in most cases women experienced the loss of their unborn child (Wall, 2012). In the absence of treatment, women are rejected from society due to shame (FMOH, 2012), and in some cases the victims are divorced and forced to live in isolation, which further pushed them into abysmal poverty (Wall, 2012).

Although there is a large chunk of OF victims living in Nigeria, merely around 5,000 sufferers were surgically treated annually; this compounds the disease circumstances (FMOH, 2012). Recently, a report of the national strategic framework for the elimination of fistula 2011-2012, country profile, Nigeria, shows that the failure to eliminate fistula in Nigeria might be related to numerous reasons, including but not limited to dearth of health facilities, unqualified health personnel, and knowledge gap about availability of treatment among others (FMOH, 2012). In addition, and more significantly, OF perhaps have continued to rise in Nigeria because the women affected by the disease are powerless to seek for competent healthcare services; owing to certain problems including, Quality of health (Morphy, Dunn, Lewis, \& Lee 2012), stigma (Dunne, Fraser, \& Gardner 2014 \& Mizck \& Russinova, 2015) and transportation (Jeremy, 2010). On the contrary, Siddle, et al. (2013), Muleta, (2008), Roush (2009), and Mukarami, Lee, Duncan, Kao, Huang, \& Singh, (2011) in their works argued that individuals could possess relatively stable health condition, transportation, and 


\section{International Journal of Engineering Applied Sciences and Technology, 2019 Vol. 4, Issue 8, ISSN No. 2455-2143, Pages 306-311 \\ Published Online December 2019 in IJEAST (http://www.ijeast.com)}

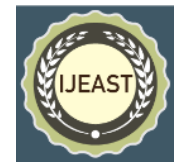

experience stigma notwithstanding, the persons search for health care services.

Based on the mixed findings established in the preceding studies, this has created gaps in knowledge that will be addressed through the introduction of the awareness campaign and rehabilitation programs to strengthen the association between the independent (quality of health, lowstigma and transportation) and dependent (health-seeking behavior) variables. According Barron and Tix (2004) moderator variable(s) can be introduced in a study if the association between independent and dependent variables is mixed, inconsistent, conflicting or weak or if there are evidences that prior programs have hospitals in Oyo, Nigeria, reported inconsistent findings. Results show that there is a positive relationship between staff attitude at the private missionary hospital and women who go to the clinic for delivery. Similarly, studies by Dunne et al. (2014) in their work regarding social support for women who visit the hospital for delivery, shows inconsistencies in their findings. Additionally, reports from the FMOH, (2012) indicated that previous intervention programs have not been effective; commensurate to the rates of the programs and high backlog of unrepaired VVF women and overall, the high number of existing cases in Nigeria.

Therefore, based on the inconsistencies among earlier studies, those have provided justification for the introduction of a moderator. According to Barron et al. (2004) a moderator is introduced if the relationship between predictor (independent variable) and an outcome (dependent variable) is inconsistent or weak. In addition and more importantly, a study can introduce an appropriate moderator if there is evidence that previous intervention program(s) have been weak or ineffective (Barron et al. 2004). Therefore, the above scenarios created a "gap" which is filled by this study through the introduction of a "moderator" to strengthen the relationship between transportation, stigma, quality of health (independent variables) and health-seeking behavior (dependent variables).

Therefore, based on the preceding discussion, this investigator was inspired to carry out a pilot study to assess the carefully chosen measuring instruments to establish their reliability and validity prior to the use of the instruments in the main study. Consequently, this study comprises of 5 major sections. The first section includes the introduction, followed by the literature review of the key constructs in section two. The third section discusses the research methodology, followed by the results of the pilot study in section four. Finally, the fifth section presented the conclusion and recommendations of the study.

\section{LITERATURE REVIEW}

\section{A. Health-seeking Behavior}

Health-seeking behavior signifies the engagement by individuals or groups with certain health challenges to promote health, prevent illness, and or treat certain diseases
(Akhter, 2015). Moreover, the construct embodies actions that comprise of commitments on the part of the patients who are experiencing apparent challenges to be willing to consent to the fact that they want to be healthy, through the acceptance of instructions from the health professionals (Wall, 2012). In addition, the concept means a sick individual working together with others to incur support in the form of therapy and general support arising from the problem that the individual presented at the healthcare facility (Akhter, 2015). The foregoing connotation of the concept demonstrates that the health practitioners that are primarily concerned with the care of the OF patients have started appreciating the idea of healthseeking behavior as an important facet of their profession. Furthermore, in relation to this concept, it is fundamental for the healthcare professional to understand some social and mental constructs as well, including, but are not limited to quality of health, stigma transportation, and more suggestively, programs that strengthen health-seeking behavior such as, awareness campaign and rehabilitation (Wall, 2012).

\section{B. Awareness campaign}

Awareness campaign programs implied to the health intervention programs offered to the community by government or non-governmental organizations through the pamphlets, posters, and radio among others, which promotes the health of a community where these services are rendered (Keating, Meakers, \& Adeniyi 2006, Karki, \& Agrawal, 2008 \& Gerten, Venkatesh, Norman, Shuaibu, \& Richter, 2009). Furthermore, health awareness campaigns are special activities, which include, but are not limited to the health education campaigns that are employed to motivate the sick individuals to look out for healthcare amenities (Bellows, Bach, Baker, \& Warren, 2015). Additionally, Bellows et al. (2015) opined that health educational campaign as an aspect of intervention programs on obstetric fistula involves the use of print and electronic media to enlighten the target audience, aimed at strengthening positive behavior towards healthseeking.

\section{Rehabilitation}

The health-related rehabilitation programs are special activities meant to encourage sick individuals to participate in health-seeking, with a view to enhancing their physical, social and mental health (FMOH, 2012). Additionally, Gerten et al (2009) stated that rehabilitation consists of activities that include but are not limited to counseling, therapy-medical and surgical, as well as skills acquisition programs among others with the aim of increasing health-seeking behavior, especially among women with OF. However, in spite of the several efforts made by the government of Nigeria through various intervention programs, including, but are not limited to thematic evaluation campaign to end fistula, obstetric fistula needs assessment, training of doctors and literacy campaign among others, the disease prevalence rate remains high 


\section{International Journal of Engineering Applied Sciences and Technology, 2019 Vol. 4, Issue 8, ISSN No. 2455-2143, Pages 306-311 \\ Published Online December 2019 in IJEAST (http://www.ijeast.com)}

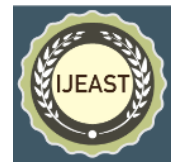

(FMOH, 2012), perhaps, according to Bellow, et al. (2014). It was because the preceding programs have not been effective Therefore, because of the ineffectiveness of the previous intervention programs in impacting on obstetric fistula women to seek for healthcare services, Bellows, et al. (2014) suggested that future studies should include appropriate programs such as awareness campaign through the radio and educational pamphlets as well as rehabilitation programs; the selection of the later programs were meant to combine with other social and psychological variables to impact on healthseeking among obstetric fistula patients in Nigeria.

\section{Quality of Health}

The Quality of health $(\mathrm{QOH})$ refers to the personal events, which incorporates freedom to express self, decent transportation, freedom of movement, happiness within one's immediate environment, upright health condition, life fulfillment, a living standard that is above average, decent housing condition, and educational attainment among others (Knopman, Zmud, Ecola, Mao, \& Crane, 2015). The concept also involves assessing clients to understand their past and present status of health (Wall, 2012). On the contrary, Knopman, et al. (2015) point out that poor quality of health represents the absence of complete physical, social and psychological well-being of an individual.

According to the World Health Organization, QOH is the totality of the individuals' consciousness of the level of their health correlated to the value system and culture in which they live, as well as in relation to their standards, objectives, concerns and prospects (Knopman, et al. 2015). In this study, QOH refers to moderately sound physical, physiological and psychological health achieved by OF patients that enable them to look out for healthcare facilities. Furthermore, it is pertinent to realize that low quality of health is a common characteristic among individuals living with chronic diseases such as Cancers, Tuberculosis, musculoskeletal pains (pains in the muscles and bones), HIV/AIDS, and other reproductive diseases (Bjomsdotis, Jonsson, \& Valdimarsdottis, 2014). On the contrary, Bjomsdotis et al. (2014) stated that decent QOH means when individuals in a given society live reasonably good socially, physically and psychologically. Additionally, the construct of QOH is important because it serves as a tool for the assessment and explanation of the outcome of disease conditions, especially conditions that are chronic ones (Borgaonkar, 2015). Furthermore, the concept of QOH can be measured both objectively and subjectively. The concept's measurement is captured objectively through focusing on things, such as quality drinking water, qualitative health infrastructure, good referral vehicles, and quality drugs among others. Subjectively, the focus of measurement encapsulates the issues such as perception of individuals with regard to satisfaction with facilities and life processes in society (Knopman, et al. 2015).

Numerous studies on QOH by Morphy, et al. (2007), Lo \& Lee, (2012) and Murakami, et al. (2011), have found some inconsistencies in their results. So for example, Lo et al. (2012) have established negative associations between sleep deprivation and quality of health. On the contrary, Morphy, et al. (2007) found a positive association between inadequate sleep and quality of health as well as improvement in subsequent health-seeking behavior. On the contrary, Murakami, et al. (2011) contends that among the County hospital population, most of the clients that reported for follow-up care are individuals with chronic illnesses. In essence, clients with less serious diseases did have lower health-seeking behavior, according to foregoing scholars.

Based on the inconsistencies in the previous studies on $\mathrm{QOH}$, those have provided justification for instituting a moderating variable in this study, which is in line with the opinions of Barron et al, (2004). In line with the preceding opinion, Bellows, et al. (2014) have suggested the introduction of awareness campaigns and rehabilitation programs to strengthen the associations between the independent variables and the dependent variable of the study. Therefore, this study used quality of health as one of the study's construct to assess its association with health-seeking behavior among obstetric fistula in the direct relationship and to combine the construct with awareness campaign and rehabilitation programs in the indirect association to evaluate the constructs within the context of some selected states in Nigeria, because this researcher believes there is the scarcity of empirical evidence in previous studies regarding this area. Thus, this study hypothesizes the following:

H1: Quality of health is positively associated with healthseeking behavior among obstetric fistula patients in Nigeria.

H2: Awareness campaign and rehabilitation programs have an impact on the association between quality of health and health-seeking behavior among obstetric fistula patients in Nigeria.

\section{E. Low-Stigma}

Stigma refers to the feeling of indignity or humiliation by a person facing certain challenging situations Siddle et al. (2013). Stigma results in prejudgment and discernment (Mizck et al. 2015). In general, the term means showing bad behavior to people arising from difference in gender, race, socioeconomic status, and health among others. Though, because the construct signifies disapproval, this study uses the term to signify low-stigma. Therefore, the construct is operationally defined as low feelings of dishonor and or humiliation displayed by OF patients that could raise their spirits to take part in programs aimed at improving their livelihood.

Numerous studies have investigated the role of stigma on health-seeking behavior among individuals with acute and chronic diseases (Mizck, et al. 2015, Siddle et al. 2013, Roush, 2009), and have found some inconsistencies in their findings. So for example, Mizck, et al. (2015) in their work reported that clients with chronic diseases such as mental 


\section{International Journal of Engineering Applied Sciences and Technology, 2019 Vol. 4, Issue 8, ISSN No. 2455-2143, Pages 306-311 \\ Published Online December 2019 in IJEAST (http://www.ijeast.com)}

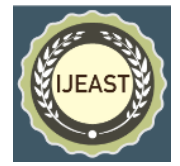

illnesses experienced stigmatization from the family, friends, and society, which affect treatment-seeking behavior due to seclusion. Conversely, studies by Siddle et al. (2013) in their work indicated that most families and friends of patients do not stigmatize them. Similarly, a study by Roush (2009) indicates that the family and friends of fistula victims treat them nicely and that the significant others support the victims to seek competent healthcare services. Similarly, $\mathrm{Ng}$, Jin, Ho \& Chua (2008) in their study of stigma among Singaporeans, indicated that stigma does not impede treatment-seeking behavior. In essence, there is a positive relationship between low-stigma and treatment-seeking. Conversely, Aromaa, Tolvanen, Tuulari \& Wahlbeck (2011) in their study among urban Singaporeans found that stigma impede health-seeking.

Based on the inconsistencies in the previous studies on stigma, those have provided justification for introducing a moderating variable in this study, which is in line with the opinions of Barron et al, (2004). In line with the preceding opinion, Bellows, et al. (2014) have suggested the introduction of awareness campaigns and rehabilitation programs to strengthen the association between the independent variables and the dependent variable of the study. Therefore, this study used stigma as one of the study's construct to assess its association with health-seeking behavior among obstetric fistula patients in the direct association and to combine the construct with awareness campaign and rehabilitation programs in the indirect association to evaluate the constructs within the context of some selected states in Nigeria, because this researcher believes there is the scarcity of empirical evidence in previous studies regarding this area. Thus, this study hypothesizes the following:

H3: Low-stigma is positively associated with health-seeking behavior among obstetric fistula patients in Nigeria.

H4: Awareness campaign and rehabilitation programs have an impact on the association between low-stigma and healthseeking behavior among obstetric fistula patients in Nigeria.

\section{F. Transportation}

Transportation means the easiness with which, information, properties, and individuals move from one place to another (Rodriguez, Comtois \& Slack, 2013). In this study, transportation refers to access to decent transportation services including, cars, buses and other vehicles and facilities that could carry obstetric fistula patients from their place of residences to health care facilities for medical assistance. The main purpose of transportation includes the satisfaction of mobility need, because transportation happens only if people, product, and info can move from one place to different place; where this is not the situation, the concept is not significant (Jeremy, 2010, Robinson, 2013 \& Rodriguez et al. 2013) On the contrary, the absence of transportation weakens the capability of the individuals in a social setting to receive information, goods, and services as well as ensure movement from one place to another (Lankowski et al. 2014). Furthermore, Syed, Gerber, \& Sharp (2013) noted that the concept of transportation is an essential tool for making sure that individuals gain access or participate in programs aimed at improving health and cure of illnesses; because every time individuals are ill, it is essential for them to visit healthcare practitioners for advice and or medication (Syed et al. 2013). Conversely, poor access to transportation may well lower the motivation of sick individuals to seek clinical intervention that could result in a decline in health conditions (Wall, 2012 \& Baba, 2014).

Several studies have examined transportation access in relation to health-seeking behavior (Strauss, Maclean, Troy, \& Litternburg 2006, \& Jeremy, 2010), and have found some inconsistencies. So for example, Jeremy (2010), observed that shortage of public transportation adversely affects utilization of healthcare facilities. On the other hand, Scheppers, Dongen, Dekker, Geertzen, \& Dekker (2006) contend that transport only affects individuals under certain condition. On the contrary, a descriptive study of driving distance and diabetes treatment by Strauss, et al. (2006) utilizing cross-sectional design reported that distance from the homes of the sick individuals to health centers does not affect consequent utilization of healthcare facilities.

Based on the inconsistencies in the previous studies on transportation, those have provided justification for instituting a moderating variable in this study, which is in line with the opinions of Barron et al, (2004). In line with the preceding opinion, Bellows, et al. (2014) have suggested for the introduction of the awareness campaign and rehabilitation programs to strengthen the associations between the independent variables and the dependent variable of the study. Thus, this study employed transportation as one of the study's construct to assess its association with health-seeking behavior among obstetric fistula in the direct relationship and to combine the construct with awareness campaign and rehabilitation programs in the indirect association to evaluate the constructs within the context of some selected states in Nigeria, because this researcher believes there is the scarcity of empirical evidence in previous studies regarding this area. Thus, this study hypothesizes the following:

H5: Transportation is positively associated with healthseeking behavior among obstetric fistula patients in Nigeria.

H6: Awareness campaign and rehabilitation programs have an impact on the association between transportation and healthseeking behavior among obstetric fistula patients in Nigeria.

\section{CONCEPTUAL MODEL}

The reviewed Literature of the concepts of this research has suggested associations between the quality of health, stigma, transportation and health-seeking behavior among the sick individuals. Specifically, previous studies by Morphy, et al. (2007), Lo et al. (2012), Murakami, et al. (2011), Mizck, et al. 


\section{International Journal of Engineering Applied Sciences and Technology, 2019 \\ Vol. 4, Issue 8, ISSN No. 2455-2143, Pages 306-311 \\ Published Online December 2019 in IJEAST (http://www.ijeast.com)}

(2015), Siddle et al. (2013), Roush, (2009), Jeremy, (2010), Robinson, (2013) \& Rodriguez et al. (2013) hypothesized direct associations between quality of health, low-stigma, transportation and health-seeking as indicated in Figure 1. Additionally, Bellows, et al. (2014) hypothesized the moderating impact of awareness campaign and rehabilitation on the associations between quality of health, stigma, transportation and health-seeking behavior among OF. Furthermore, the theory of planned behavior (TPB) and health beliefs model (HBM) conjectured direct and indirect associations between the constructs of interest to this study. In the direct association, the TPB proposed that the more positive the attitude (A), subjective norms (SN) and perceived behavioral control (PBC) the vigorous the health-seeking behavior among OF patients. Conversely the negative the attitude to seek healthcare services, the less encouraging the opinions of significant others, as well as the less individuals have confidence about their abilities, power, and control over seeking help, the slighter the chances for the patients to look out for medical help. Moreover, in the indirect association, the HBM suggested that the threat of complications of diseases and perceived benefits of treatment drive patients to tackle challenges of quality of health, stigma and transportation, as well as make use of awareness campaigns and rehabilitation programs that promote health-seeking behavior.

Therefore, the six constructs adapted in the proposed conceptual model (see Figure 1), when validated through this research, will be engaged for further investigations in the social context of Nigeria. Furthermore, the future study will utilized a vigorous methodological orientation (pragmatism) and method (quantitative and qualitative) as well as institute awareness campaign and rehabilitation programs in a single study to evaluate the impact of the programs, when combined with the quality of health, low-stigma and transportation in strengthening the health-seeking behavior among OF patients in Nigeria.

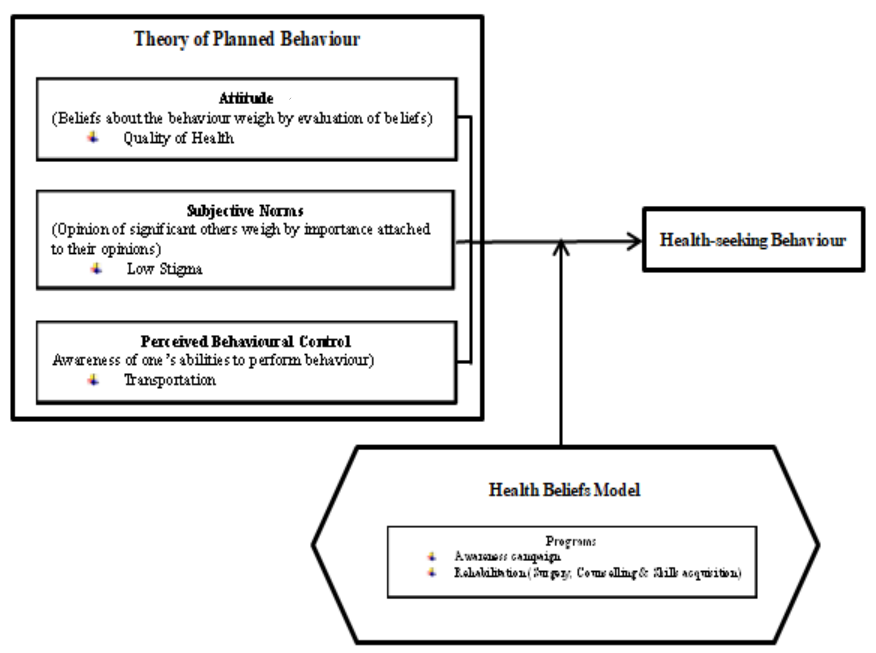

Figure.1 Proposed Conceptual Model

\section{CONCLUSION AND RECOMMENDATION}

To conclude, this study was designed to evaluate and validate constructs on the impact of awareness campaigns and rehabilitation on the association between quality of health, stigma, transportation and health-seeking behavior among OF patients in Nigeria. For the time being, this study offered a theoretical model that could serve as a reference point to researchers that wish to conduct future study regarding exactly how awareness campaign and rehabilitation programs, combined with quality of health, stigma, and transportation possibly will reinforce health-seeking behavior among OF patients. For that reason, as soon as this proposed conceptual model is validated, its outcome will offer significant contributions to literature meant for policymakers on healthcare, health practitioners and academicians among others, so that they can make earnest decisions for the overall development of society.

In the interim, the limitation of the preceding conceptual model developed in this study remains its failure to include several significant independent variables in the direct association as well as a mediator variable in the indirect association. Therefore, this scholar recommends the addition of more social and psychological variables as well as a mediator variable into the current model for further confirmations.

\section{REFERENCES}

[1] Akhter, S. (2015). Maternal health care-seeking behavior of women from lower and socio-economic groups of Dhaka, Bangladesh-fear or fusion? A Doctoral (PhD) dissertation thesis. (pp. 22-51)

[2] Aromaa, E., Tolvanen, A., [Tuulari, J. \& Wahlbeck, K.(2011) Personal Stigma and use of mental health services among people with depression in general population in Finland. Biomedic central psychology, (pp. 124-131)

[3] Barron, K. E. \& Tix, A. P. (2004) Testing moderator and mediator effects in counselling psych ology research. Journal of counselling psychology. (pp. 115-134)

[4] Bellows, B., Bach, R., Baker, Z. \& Warren, C. (2014) Barriers to obstetric fistula treatment in low- income countries: A systematic review, Population council. 2014.

[5] Bjomsdotis, S. V., Jonsson, S. H., \& Valdimarsdottis, U. A. (2014). Mental health indicators and quality of life among individuals with musculoskeletal chronic pain: a nationwide study in Iceland. Scand journal rheumatoid. (pp. 423-431).

Federal Ministry of Health (2012). National Strategic Framework for the Elimination of Obstetric fistula in Nigeria, 2011-2015. (pp.7-20) 


\section{International Journal of Engineering Applied Sciences and Technology, 2019 \\ Vol. 4, Issue 8, ISSN No. 2455-2143, Pages 306-311 \\ Published Online December 2019 in IJEAST (http://www.ijeast.com)}

[7] Gerten, K. A.. Venkatesh, S., Norman, A. M., Shuaibu, J., \& Ritchter, H. (2009) Pilot study utilizing a patient educational brochure to a vesicovaginal fistula, Hospital in Nigeria, Africa. International urogynecol journal pelvic floor dysfunct -ion. (pp. 22-37).

[8] Jeremy, M. Transportation, distance and healthcare utilization for older adults in rural and small urban areas (2010). Small Urban and Rural transit center, Upper Great Plains transportation institute, North Dakota State University, Fargo. (pp. 12-34)

[9] Karki, Y. B. \& Agrawal, G. (2008). Effects of communication campaigns on health behaviour of women of reproductive age in Nepal. Further analysis of 2006. Nepal ddemographic and health survey. (pp. 12-34)

[10] Keating, J. Meakers, D. \& Adeniyi, (2006) A. Assessing effects of media campaign on HIV/AIDS awareness and prevention in Nigeria: results from the vision project. Biomed central. (pp. 43-52)

[11] Knopman, D. Zmud, J. Ecola, L., Mao, Z. \& Crane, K. (2015) Quality of life indicators and policy strategies to advance sustainability in the Pearl River Delta. RAND Corporation, Santa Monica. (pp. 1-3)

[12] Lo, C. M. \& Lee P. H. (2012) Prevalence and impacts of poor sleep on quality of life and associated factors of good sleepers in a sample of older Chinese adults.Health quality of life, biomed central. (pp. 111-117)

[13] Mizck, L. S. \& Russinova, Z. (2015). Intersectional stigma and the acceptance process of women with mental illness. Women and theraphy, (pp. 14-30).

[14] Morphy H., Dunn, K. M., Lewis, M., Boardman, H. F. \& Craft, P. R. (2007). Epidemiology of Insomnia: a longitudinal study in a UK population, Sleep, pubmed, (pp. 274-280).

[15] Murakami, Y., Lee, B.w., Duncan, M., Kao, A., Huang, J. Singh, K., \& Lin, S. C. (2011) Racial disparities in adherence to glaucoma follow up visit in a county hospital population. Arch. Opthalmol, (pp. 872-878).

[16] Ng T. P., Jin, A. Z., Ho, R., Chua, H. C. (2008) Health beliefs and help-seeking for depressive and anxiety disorder among urban Singaporean adults. Psychiatr (pp. 234-239)

[17] Rodrigue, J. P., Comtois, C. \& Slack, B. (2013). The geography of transport system. Routledge publishers, New York, NY. Dimension. (pp. 1-16)

[18] Roush, K. M. (2009). Social implication of obstetric fistula: An integrative review. Journal of midwifery \& women \& women's health. (pp. 21-33).

[19] Scheppers, E., Dongen, E. V., Dekker, J., Geertzen, J. \& Dekker, J. (2006). Potential barriers to use of health services among ethnic minorities: a review. Family practice advances. (45-53)
[20] Siddle, K., Mwambingu, s., Malinga, T. \& Fiander (2013). A. Psychosocial impact of obstetric fistula in women presenting for surgical care in Tanzania.International gyenecol journal, (pp. 12151220)

[21] Strauss, K., Maclean, C., Troy, A. \& Litternburg, B. (2006). Driving distance as a barrier to glyceric control in diabetes. Journal of general internal medicine. (378-380).

[22] Wall, L. L. (2012). Overcoming phase 1 delays: the critical components of obstetric fistula prevention programs in resources-poor countries. Wall BMC pregnancy and childbirth. (pp. 1-13). 